\title{
Short-Term Prophylaxis in Odontostomatological, Maxillofacial and ENT Procedures in Patients with Hereditary Angioedema Due to C1-Inhibitor Deficiency
}

\author{
Jesús Jurado-Palomo and Teresa Caballero \\ Additional information is available at the end of the chapter
}

http://dx.doi.org/10.5772/67713

\begin{abstract}
Oestrogens, trauma, infections or stress has been described as triggers for angioedema (AE) attacks in patients with hereditary angioedema due to C1-inhibitor deficiency (C1-INH-HAE). Microtrauma can precipitate the onset of acute AE attacks, and thus, dental-oral procedures carry a high risk of triggering them and also an increased risk of death from asphyxiation due to the AE location. In the past, without proper specific treatment, the overall mortality after dental surgery in patients with C1-INH-HAE was up to $30-40 \%$. Some dental-oral, medical and/or surgical procedures are susceptible to receive "short-term prophylaxis" (STP) in order to reduce the risk of AE. We describe the published case reports of dental-oral, maxillofacial and ear, nose and throat (ENT) procedures in patients with C1-INH-HAE. Different consensus algorithms and clinical guidelines have been published for managing dental-oral, maxillofacial and otolaryngological procedures (DOMFOPs) and will be reviewed below. Based on the clinical experience of the Department of Allergology of the University Hospital La Paz (Madrid) and the University General Hospital Nuestra Señora del Prado (Talavera de la Reina), these algorithms have been updated and modified. We advise to classify procedures according to the risk of producing $\mathrm{AE}$ as minor, intermediate and major risks.
\end{abstract}

Keywords: algorithm, angioedema, antifibrinolytic agents, attenuated androgens, bradykinin, C1 inhibitor, dental-oral procedures, dental surgery, ecallantide, hereditary angioedema, icatibant acetate, recombinant human $\mathrm{C} 1$ inhibitor, plasma-derived human C1-inhibitor concentrate, short-term prophylaxis, solvent/detergent-treated plasma, treatment 


\section{Introduction}

Hereditary angioedema due to C1-inhibitor deficiency (C1-INH-HAE) is a genetic autosomal dominant disease characterized by a deficiency of the functionally active $\mathrm{C} 1$ esterase inhibitor (C1-INH) protein [1]. This deficiency results in an excess of bradykinin (BK), which increases vascular permeability and produces angioedema (AE) [1].

The minimum prevalence of C1-INH-HAE is 1.09 per 100,000 inhabitants in Spain [2], 1.41 per 100,000 inhabitants in Denmark [3], 1.54 per 100,000 inhabitants in Italy [4] and 1.75 per 100,000 inhabitants in Norway [5].

Other forms of BK-mediated AE are: acquired angioedema due to C1-INH deficiency (C1-INHAAE), hereditary angioedema with normal C1-INH (C1-INH-nC1-INH), with/without mutation in the F12 gene that encodes Factor XII coagulation (HAE-FXII/HAE-D) and acquired angioedema associated with angiotensin converting enzyme inhibitors (ACEi) (AAE-ACEi). ACEis are drugs that inhibit the metabolic pathways of BK and thus produce an increase in BK. Other drugs that inhibit BK catabolism have been implicated in the development of AE. These include dipeptidyl peptidase IV (DPPIV) inhibitors, aminopeptidase P (APP) inhibitors, neutral endopeptidase (NEP) inhibitors and others. In this chapter, we will focus on C1-INH-HAE.

\section{The importance of cervicofacial anatomical location in C1-INH-HAE angioedema attacks}

Oestrogens, trauma, infections or stress has been described as triggers for AE attacks in 21 patients with C1-INH-HAE [6]. Microtrauma can precipitate the onset of acute AE attacks, and thus, dental-oral procedures carry a high risk of triggering them and also an increased risk of death from asphyxiation due to the AE location [7]. Treatment with adrenaline, antihistamines or glucocorticoids is not effective in this type of BK-mediated AE [8].

In the past, without proper specific treatment, overall mortality after dental surgery in patients with C1-INH-HAE was up to 30-40\% [9-12]. Some dental-oral, medical and/or surgical procedures are susceptible to receive "short-term prophylaxis" (STP) (also called "pre-procedural prophylaxis") $[8,13-15]$ in order to reduce the risk of AE. Such prophylaxis in patients with C1-INH-HAE usually consists of introducing oral antifibrinolytics or attenuated androgens (AAs) or administering intravenous pdhC1INH before the procedure [8, 13]. There are currently two brands of pdhC1INH available: Berinert ${ }^{\circledR}$ (CSL-Behring, Marburg, Germany) and Cinryze $^{\circledR}$ (Shire-HGT, Zug, Switzerland). Since upper airway AE can cause death from asphyxiation $[13,16]$, adequate monitoring of upper airway permeability is imperative, so that appropriate emergency treatment (endotracheal intubation and/or tracheotomy) is performed if the upper airway is threatened despite medical treatment $[8,17]$. Nevertheless, the availability of specific drugs for the treatment of acute AE attacks and of plasma-derived human C1-inhibitor concentrates (pdhC1INH) (Berinert ${ }^{\circledR}$, CSL Behring, Marburg, Germany and Cinryze $^{\circledR}$, Shire HGT, Zug, Switzerland) for STP, together with the increased awareness of 
pre-procedural prophylaxis, has reduced the prevalence of upper airway respiratory $\mathrm{AE}$ and death from asphyxiation after dental procedures [15, 18].

\section{Management of dental-oral, maxillofacial and ENT procedures (DOMFOPs) in patients with C1-INH-HAE}

A review of published case reports of dental-oral, maxillofacial and ear, nose and throat (ENT) procedures in patients with C1-INH-HAE is shown in Table 1.

\begin{tabular}{|c|c|c|c|c|c|c|}
\hline \multirow[t]{2}{*}{ Case report (gender/age) } & \multicolumn{3}{|l|}{ STP } & \multirow[t]{2}{*}{ AE type } & \multirow{2}{*}{$\begin{array}{l}\text { AE } \\
\text { development }\end{array}$} & \multirow[t]{2}{*}{ Reference } \\
\hline & pdhC1INH & FFP & $\begin{array}{l}\text { Icatibant } \\
\text { acetate }\end{array}$ & & & \\
\hline $\begin{array}{l}\text { One male and five females aged } \\
\text { between } 18 \text { and } 64 \text { y.o. }\end{array}$ & N.AD & 2 Units & N.AD & $\begin{array}{l}\text { C1-INH-HAE } \\
\text { type I }\end{array}$ & None & Jaffe et al. [19] \\
\hline $\begin{array}{l}\text { Three males aged between } 41 \text { and } \\
56 \text { y.o. }\end{array}$ & N.AD & N.AD & N.AD & C1-INH-HAE & None & $\begin{array}{l}\text { Heft and } \\
\text { Flynn [20] }\end{array}$ \\
\hline One female of 28 y.o. & N.AD & N.AD & N.AD & C1-INH-HAE & None & \\
\hline One female of 45 y.o. & N.AD & 1 Unit & N.AD & $\begin{array}{l}\text { C1-INH-HAE } \\
\text { type I }\end{array}$ & None & $\begin{array}{l}\text { Delfino et al. } \\
\text { [21] }\end{array}$ \\
\hline One female of 22 y.o. & N.AD & 2 Units & N.AD & $\begin{array}{l}\text { C1-INH-HAE } \\
\text { type I }\end{array}$ & None & $\begin{array}{l}\text { Allbright and } \\
\text { Taylor [22] }\end{array}$ \\
\hline One male of 20 y.o. & N.AD & N.AD & N.AD & C1-INH-HAE & None & $\begin{array}{l}\text { Sturdy et al. } \\
{[23]}\end{array}$ \\
\hline One female of 32 y.o. & N.AD & 2 Units & N.AD & $\begin{array}{l}\text { C1-INH-HAE } \\
\text { type I }\end{array}$ & None & $\begin{array}{l}\text { Mauro et al. } \\
\text { [24] }\end{array}$ \\
\hline One male of 37 y.o. & N.AD & 2 Units & N.AD & Unknown & None & $\begin{array}{l}\text { Malmstrom } \\
\text { et al. [25] }\end{array}$ \\
\hline One female of 40 y.o. & N.AD & 4 Units & N.AD & $\begin{array}{l}\text { C1-INH-AAE } \\
\text { type II }\end{array}$ & $\begin{array}{l}\text { Laryngeal } \\
\text { oedema }\end{array}$ & $\begin{array}{l}\text { Degroote } \\
\text { et al. [26] }\end{array}$ \\
\hline One male of 32 y.o. & N.AD & 6 Units & N.AD & $\begin{array}{l}\text { C1-INH-HAE } \\
\text { type I }\end{array}$ & None & $\begin{array}{l}\text { Phillips et al. } \\
\text { [27] }\end{array}$ \\
\hline \multirow[t]{2}{*}{ One female of 18 y.o. } & $2000 \mathrm{IU}$ & N.AD & N.AD & \multirow{2}{*}{$\begin{array}{l}\text { C1-INH-HAE } \\
\text { type I }\end{array}$} & None & \multirow{2}{*}{$\begin{array}{l}\text { Leimgruber } \\
\text { et al. [28] }\end{array}$} \\
\hline & N.AD & N.AD & N.AD & & $\begin{array}{l}\text { Laryngeal } \\
\text { oedema }\end{array}$ & \\
\hline \multirow[t]{2}{*}{$\begin{array}{l}\text { One male and two females aged } \\
\text { between } 34 \text { and } 49 \text { y.o. }\end{array}$} & N.AD & 4 Units & N.AD & $\begin{array}{l}\text { C1-INH-HAE } \\
\text { type I }\end{array}$ & None & \multirow[t]{2}{*}{$\begin{array}{l}\text { Peled et al. } \\
\text { [29] }\end{array}$} \\
\hline & N.AD & 4 Units & N.AD & $\begin{array}{l}\text { C1-INH-HAE } \\
\text { type I }\end{array}$ & None & \\
\hline One female of 10 y.o. & N.AD & 2 Units & N.AD & $\begin{array}{l}\text { C1-INH-HAE } \\
\text { type I }\end{array}$ & None & $\begin{array}{l}\text { Karlis et al. } \\
{[30]}\end{array}$ \\
\hline
\end{tabular}




\begin{tabular}{|c|c|c|c|c|c|c|}
\hline \multirow[t]{2}{*}{ Case report (gender/age) } & \multicolumn{3}{|l|}{ STP } & \multirow[t]{2}{*}{ AE type } & \multirow{2}{*}{$\begin{array}{l}\text { AE } \\
\text { development }\end{array}$} & \multirow[t]{2}{*}{ Reference } \\
\hline & pdhC1INH & FFP & $\begin{array}{l}\text { Icatibant } \\
\text { acetate }\end{array}$ & & & \\
\hline $\begin{array}{l}\text { Six males and six females aged } \\
\text { between } 21 \text { and } 50 \text { y.o. }\end{array}$ & N.AD & N.AD & N.AD & $\begin{array}{l}\text { C1-INH-HAE } \\
\text { type I }\end{array}$ & None & $\begin{array}{l}\text { Farkas et al. } \\
{[31]}\end{array}$ \\
\hline One male of 4 y.o. & N.AD & Used & N.AD & Unknown & None & Webb et al. \\
\hline One female of 6 y.o. & N.AD & N.AD & N.AD & HAE & None & [32] \\
\hline One female of 54 y.o. & $500 \mathrm{IU}$ & N.AD & N.AD & $\begin{array}{l}\text { C1-INH-HAE } \\
\text { type I }\end{array}$ & None & $\begin{array}{l}\text { Maeda et al. } \\
{[33]}\end{array}$ \\
\hline $\begin{array}{l}\text { Three females aged between of } 27 \\
\text { and } 32 \text { y.o. }\end{array}$ & N.AD & N.AD & N.AD & $\begin{array}{l}\text { C1-INH-HAE } \\
\text { type I }\end{array}$ & $\begin{array}{l}\text { Laryngeal } \\
\text { oedema }\end{array}$ & $\begin{array}{l}\text { Börk and } \\
\text { Barnstedt [18] }\end{array}$ \\
\hline One male of 46 y.o. & N.AD & N.AD & N.AD & $\begin{array}{l}\text { C1-INH-HAE } \\
\text { type I }\end{array}$ & $\begin{array}{l}\text { Laryngeal } \\
\text { oedema }\end{array}$ & \\
\hline One female of 28 y.o. & N.AD & N.AD & N.AD & $\begin{array}{l}\text { C1-INH-HAE } \\
\text { type I }\end{array}$ & $\begin{array}{l}\text { Laryngeal } \\
\text { oedema }\end{array}$ & Rice et al. [34] \\
\hline One female of 49 y.o. & N.AD & N.AD & N.AD & $\begin{array}{l}\text { C1-INH-HAE } \\
\text { type I + AAE- } \\
\text { ACEi }\end{array}$ & $\begin{array}{l}\text { Laryngeal } \\
\text { oedema }\end{array}$ & $\begin{array}{l}\text { Van Sickels } \\
\text { et al. [35] }\end{array}$ \\
\hline One female of 33 y.o. & N.AD & N.AD & N.AD & $\begin{array}{l}\text { C1-INH-HAE } \\
\text { type I }\end{array}$ & $\begin{array}{l}\text { None } \\
\text { (danazol) }\end{array}$ & \\
\hline One female of 8 y.o. & Used & N.AD & N.AD & C1-INH-HAE & $\begin{array}{l}\text { None } \\
\text { (danazol) }\end{array}$ & $\begin{array}{l}\text { Moraes et al. } \\
{[36]}\end{array}$ \\
\hline \multirow[t]{2}{*}{ One male of 36 y.o. } & N.AD & N.AD & N.AD & $\begin{array}{l}\text { C1-INH-HAE } \\
\text { type II }\end{array}$ & $\begin{array}{l}\text { Laryngeal } \\
\text { oedema }\end{array}$ & $\begin{array}{l}\text { Baccioglu } \\
\text { Kavut [37] }\end{array}$ \\
\hline & $1000 \mathrm{IU}$ & N.AD & N.AD & & None & \\
\hline One female of 28 y.o. & N.AD & N.AD & $\mathrm{SC} 30 \mathrm{mg}$ & $\begin{array}{l}\text { C1-INH-HAE } \\
\text { type I }\end{array}$ & None & $\begin{array}{l}\text { Senaratne } \\
\text { et al. [38] }\end{array}$ \\
\hline One female of 45 y.o. & N.AD & N.AD & SC $30 \mathrm{mg}$ & C1-INH-HAE & None & $\begin{array}{l}\text { Angeletti } \\
\text { et al. [39] }\end{array}$ \\
\hline One female of 6 y.o. & $500 \mathrm{IU}$ & N.AD & N.AD & $\begin{array}{l}\text { C1-INH-HAE } \\
\text { type II }\end{array}$ & None & $\begin{array}{l}\text { Narayanan } \\
\text { et al. [40] }\end{array}$ \\
\hline $\begin{array}{l}\text { Two males aged between } 19 \text { and } \\
57 \text { y.o. and one female of } 20 \text { y.o. }\end{array}$ & N.AD & N.AD & N.AD & $\begin{array}{l}\text { C1-INH-HAE } \\
\text { type I }\end{array}$ & $\begin{array}{l}\text { Minimal } \\
\text { pharyngeal } \\
\text { oedema }\end{array}$ & $\begin{array}{l}\text { Jurado- } \\
\text { Palomo et al. } \\
{[15]}\end{array}$ \\
\hline One female of 26 y.o. & $1000 \mathrm{IU}$ & N.AD & N.AD & $\begin{array}{l}\text { C1-INH-HAE } \\
\text { type I }\end{array}$ & None & $\begin{array}{l}\text { Sanuki et al. } \\
\text { [41] }\end{array}$ \\
\hline One female of 50 y.o. & N.AD & N.AD & N.AD & C1-INH-HAE & $\begin{array}{l}\text { Laryngeal } \\
\text { oedema }\end{array}$ & $\begin{array}{l}\text { Forrest et al. } \\
\text { [42] }\end{array}$ \\
\hline
\end{tabular}

$\mathrm{FFP}=$ fresh frozen plasma, $\mathrm{IU}=$ International Unit, $\mathrm{N} . \mathrm{AD}=$ not administered, pdhC1INH $=$ plasma-derived human $\mathrm{C} 1$ esterase inhibitor, $\mathrm{SC}=$ subcutaneous, $\mathrm{STP}=$ short-term prophylaxis and y.o. = years old.

Table 1. Literature review of dental-oral, maxillofacial and ENT procedures in patients with C1-INH-HAE. 


\section{The development of diagnostic-therapeutic algorithms for dental-oral, maxillofacial and otolaryngological procedures (DOMFOPs) according to the risk of triggering angioedema attacks}

In the last 12 years, different consensus algorithms and clinical guidelines have been published for managing DOMFOP STP and will be reviewed below.

\subsection{The 2003 Hungarian-Canadian consensus algorithm}

The 2003 Hungarian-Canadian consensus was the first consensus document on the management of C1-INH-HAE [43]. It attempted to establish a separation between minor and major DOMFOPs but did not go deeper in differentiating clearly which procedures were considered minor or major (Figure 1) [43].

According to the 2003 Hungarian-Canadian consensus, the STP in DOMFOPs should be as follows:

1. If only a minimum dental manipulation was going to be performed and pdhC1INH was available for the treatment of acute AE attacks, no pre-procedural prophylaxis was indicated. However, if pdhC1INH was not available, STP with danazol or tranexamic acid was recommended. Local injection of local anaesthetic was recognized as being able to precipitate an AE attack [43].

2. For a manipulation that was not considered minor, danazol was recommended (even in children and pregnant women in the last trimester). Tranexamic acid was considered as an

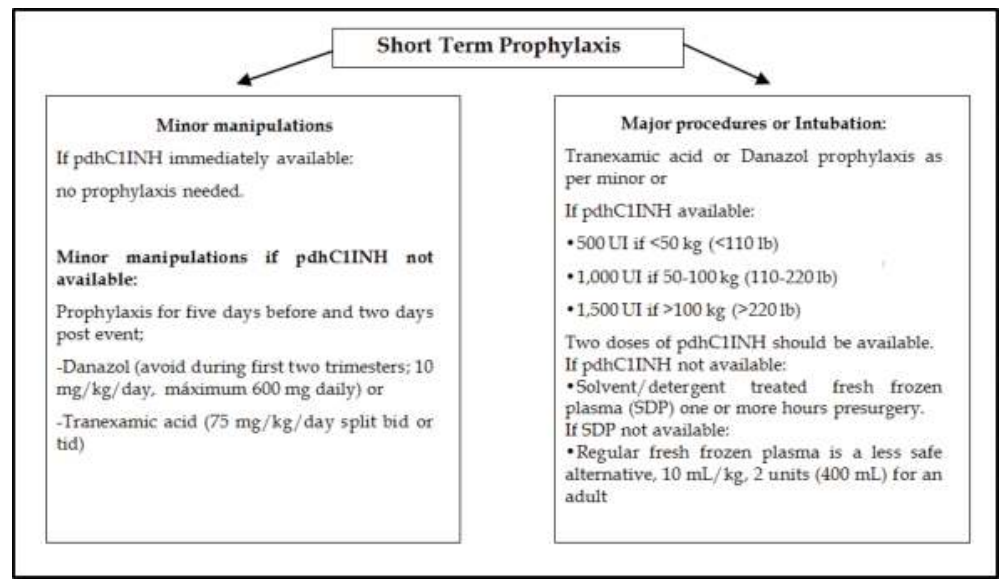

Figure 1. Short-term prophylaxis algorithm for C1-inhibitor deficiency according to the 2003 Hungarian-Canadian consensus [43]. 
alternative to danazol. pdhC1INH should be available for immediate administration if an $\mathrm{AE}$ attack developed [43]. In case of a major surgical procedure or if the patient was being intubated, intravenous pdhC1INH had to be administered 1 hour before surgery. A second pdhC1INH dose should be administered during surgery and even repeated daily or as much as needed until there was no risk of developing AE. If pdhC1INH was not available, STP with danazol or tranexamic acid was recommended. Solvent/detergenttreated fresh frozen plasma (SD-FFP) 1 or more hours before procedure could be another alternative if pdhC1INH was not available; regular FFP would be a fourth option, although less safe than SD-FFP [43].

The algorithm summarizing the recommendations for surgical risk of the Hungarian-Canadian consensus 2003 can be seen in Figure 1 [43].

\subsection{The 2005 British consensus algorithm}

According to the 2005 British consensus [16], STP was not only indicated before risky procedures or surgeries but also during periods of physiological or psychological stress (also called intermittent long-term prophylaxis). It was the first time that the term "intermittent long-term prophylaxis" was used. The proposed STP scheme was as follows:

- pdhC1INH (500-1500 U, generally 1000 U) up to 24 hours before. Additional doses may be required later, basically if postoperative infection occurs. It was the treatment of choice in major dental procedures such as tooth extractions.

- Tranexamic acid from 2 to 5 days before procedure until 2 days after procedure $-4 \mathrm{~g} /$ day (1 g 4 times/day)

- Attenuated androgens from 2 to 5 days before procedure to 2 days after procedure

- Danazol: 100-600 mg/day

- Stanozolol: 2-6 mg/day

\subsection{The 2007 Hungarian-Canadian consensus algorithm}

The 2007 Hungarian-Canadian consensus (published in 2008) continued the distinction between minor or major procedures and intubation (Figure 2) [44].

Unlike the 2003 Hungarian-Canadian algorithm, the recommendation of the use of tranexamic acid in minor manipulations with available pdhC1INH was removed. In addition, in major procedures or intubation, the recommendation of the use of danazol or tranexamic acid was also removed, and recommendations differed according to the availability or non-availability of pdhC1INH.

\subsection{The 2010 international consensus algorithm}

The International consensus published in Allergy, Asthma and Clinical Immunology (official publication of the Canadian Society of Allergy and Clinical Immunology) in 2010 updated the STP recommendations (Figure 3) [13]. 


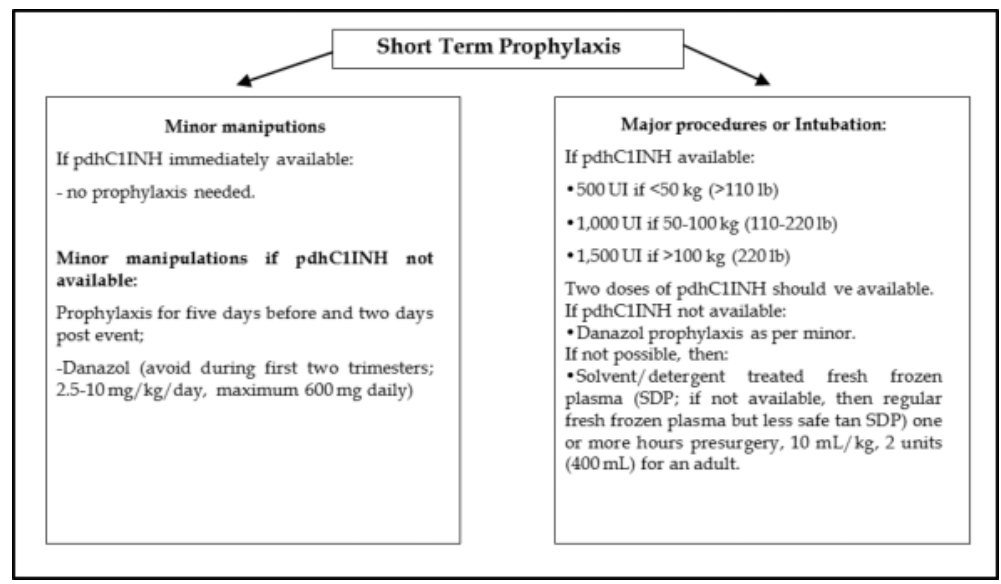

Figure 2. Prophylaxis algorithm in C1-inhibitor deficiency of the 2007 Hungarian-Canadian consensus [44].

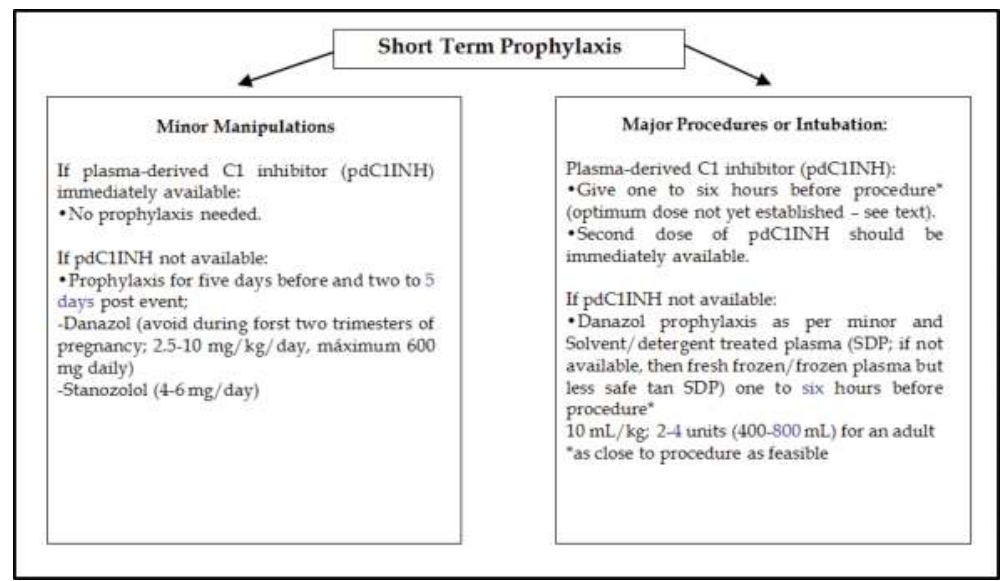

Figure 3. Prophylaxis algorithm in C1-inhibitor deficiency in the 2010 international consensus [44].

A distinctive feature is that the time period for STP with oral drugs for minor risk procedures was increased from 5 days before the procedure to 2-5 days after the completion of the procedure [13]. It also emphasizes the non-use of danazol during the first two trimesters of pregnancy because of the obvious risks of AAs. Antifibrinolytics are still not recommended for STP in this type of procedures.

In procedures involving a higher AE risk or endotracheal intubation, pdhC1INH should be administered from 1 to 6 hours before the procedure, if available. As in previous consensus documents, it only distinguishes between DOMFOPs of minor or major risk, not considering "intermediate risk". 


\subsection{The 2011 Spanish consensus algorithm}

According to the Spanish consensus [8], STP was indicated in surgery or medical procedures that involve trauma in the cervicofacial region with the risk of laryngeal oedema development (e.g. dental manipulations, tonsillectomy, maxillofacial surgery, endoscopy, bronchoscopy or interventions requiring endotracheal intubation) and to prevent local oedema that could alter the surgeon's work area and may affect the surgical outcome.

Specific acute treatment (pdhC1INH or icatibant acetate) must be available with appropriate monitoring of the patient after surgery, including an action plan.

The recommendations were as follows:

- Intravenous pdhC1INH (500 U if the patient weighs less than $50 \mathrm{~kg}$ and $1000 \mathrm{U}$ if he/she weighs more than $50 \mathrm{~kg}$ ) administered from 1 to 4 hours prior to the procedure, with a required second dose (if available).

- Intravenous SD-FFP (if pdhC1INH is not available), two units administered 1 hour before the procedure.

- AAs from 5 to 7 days before to 2-3 days after the procedure (in case of postoperative complications such as infections, AAs should be continued for more than 5 days.)

- Danazol: 400-600 mg/day

- Stanozolol: 4-6 mg/day

- Antifibrinolytics

- EACA

- Tranexamic acid: 1-4 g/day or $75 \mathrm{mg} / \mathrm{kg} /$ day divided into 2-3 doses from 5 days before to 2 days after surgery

Drugs and doses for STP are summarized in Table 2.

\begin{tabular}{llll}
\hline $\begin{array}{l}\text { Pharmacological } \\
\text { group }\end{array}$ & Drug & Adults & Children \\
\hline C1-INH replacement & pdhC1INH & $500-1500 \mathrm{U}, 1-4$ hours before event & $20 \mathrm{U} / \mathrm{kg}, 1$ hour before event \\
& FFP & $2 \mathrm{U}(400 \mathrm{ml}), 1$ hour before procedure & $10 \mathrm{~mL} / \mathrm{kg} 1$ hour before procedure \\
$\begin{array}{l}\text { Attenuated } \\
\text { androgens }\end{array}$ & Danazol & $\begin{array}{l}400-600 \mathrm{mg} / 24 \text { hours for } 5-7 \text { days before and } \\
2-3 \text { days post-event }\end{array}$ & $\begin{array}{l}10 \mathrm{mg} / \mathrm{kg} / \text { day for } 5-7 \text { days before to } \\
2-3 \text { days post-event }\end{array}$ \\
& Stanozolol & $\begin{array}{l}4-6 \mathrm{mg} / 24 \text { hours for } 5 \text { days before and } 3 \text { days } \\
\text { post-event }\end{array}$ & \\
$\begin{array}{l}\text { Antifibrinolytics } \\
\text { (seldom used) }\end{array}$ & $\begin{array}{l}\text { Tranexamic } \\
\text { acid }\end{array}$ & $\begin{array}{l}1 \text { g/6 hours for } 5 \text { days before and } 2 \text { days } \\
\text { post-event }\end{array}$ & $\begin{array}{l}500 \mathrm{mg} / 6 \text { hours for } 2 \text { days before and } \\
2 \text { days post-event }\end{array}$ \\
\hline
\end{tabular}

Table 2. Short-term prophylaxis in the Spanish 2011 national consensus on C1-INH-HAE. 


\subsection{The 2012 management guidelines of the World Allergy Organization (WAO)}

This was the first guideline on C1-INH-HAE and thus was the first time in which evidence levels were analysed and graded recommendations were given [45].

There was no evidence about the effectiveness of STP. The advice to administer STP was based on Expert Opinion. It was stated that even though STP was used, AE episodes could still occur and sometimes after minor procedures (case reports, series of patients). Nevertheless, several publications had reported a reduction in the incidence of AE with STP in both adults and children. In this guideline, the indications of STP varied according to:

- The patient's personal history: frequent episodes of $\mathrm{AE}, \mathrm{AE}$ following a similar procedure (dental or oral surgery), need for intubation, more invasive procedures

- Probability of AE associated with such a procedure

- Periods of high risk of attacks (due to increased likelihood of AE attacks or increased consequences of $\mathrm{AE}$ attack): periods of stress, tests

STP administration had to be considered prior to surgery, especially in the case of dental/ intraoral procedures, in which endotracheal intubation was required, when the airway or pharynx was manipulated and before bronchoscopy or endoscopy. This statement had a level of evidence D (adapted from previous consensus document or "statement" based on an expert opinion poll during a consensus conference) and a strength of recommendation A.

In DOMFOPs with minimal risk or if there was availability of safe drugs for on-demand treatment of "upper airway edema" (UAE) attacks, STP could be omitted. Two doses of pdhC1INH, ecallantide or icatibant had to be available for possible immediate administration. The patient had to know the risks and have a plan of action and treatment for AE attacks.

The recommendations were as follows:

- Intravenous pdhC1INH: $10-20 \mathrm{U} / \mathrm{kg}$ or $1000 \mathrm{U}$ was recommended, administered from 1 to 6 hours before DOMFOP. Dosing studies were required, as AE attacks have even occurred with $1000 \mathrm{U}$ doses

- SD-FFP (if pdhC1INH was not available)

- AAs from 5 days before to 5 days after the procedure (if the risk associated with the procedure or surgery was relatively low and no pdhC1INH was available). Its use was limited to elective surgery with a lower perceived effectiveness as compared to pdhC1INH, although there was no evidence. AAs have considerable side effects, being contraindicated during pregnancy (except in the last trimester of pregnancy) and during lactation

- Danazol: 2.5-10 mg/kg/day, to a maximum dose of $600 \mathrm{mg} /$ day

- Stanozolol: 4-6 mg/day

- Antifibrinolytics

- Tranexamic acid: $25 \mathrm{mg} / \mathrm{kg} /$ day divided into $2-3$ doses 


\subsection{The 2013 guidelines for the management of HAE, C1-INH-AAE and ACEi-AAE}

All HAE patients are candidates for STP when exposed to situations that could likely trigger an AE attack [46].

Two statements are particularly relevant in this field:

1. Summary statement 20: STP can be achieved by using FFP, pdhC1INH and high doses of AAs for short periods. Recommendation strength B (directly based on category II evidence or recommendation extrapolated from category I evidence).

2. Summary statement 25: New drugs for the treatment of C1-INH deficiency syndromes are costlier than the alternative treatment with AAs. Official studies of cost-utility and costeffectiveness in helping healthcare providers in the management of patients with C1-INH deficiency syndromes are warranted. Strength of recommendation D.

The drugs and doses recommended are as follows:

- Intravenous pdhC1INH: 1000-2000 U

- Intravenous SD-FFP 2 U: several hours (up to 12 hours) before the procedure

- Oral 17-alpha-alkylated AAs, for 5-10 days before to 2 days after the procedure

- Danazol: 6-10 mg/kg/day into divided doses; maximum $200 \mathrm{mg}$, 3 times per day or equivalent

There are no comparative studies between pdhC1INH and AAs. The decision on the drug to be prescribed should be based on an individualized assessment of damage/burden compared to the benefits, costs and patient preferences. In emergency procedures, pdhC1INH is the treatment of choice. Specific treatment for AE attacks (pdhC1INH, ecallantide or icatibant) should be available during and after any procedure.

\subsection{The 2014 Canadian consensus}

STP should be considered prior to the patient's specific known triggers and before any medical, surgical or dental procedures [47]. Evidence level is low, and the strength of the recommendation is strong.

Specific treatments for the acute attack of C1-INH-HAE should be available during and after the procedure. The level of evidence is low (our confidence in the estimated effect is limited: the true effect may be substantially different from the estimated effect). The strength of the recommendation is strong.

The drugs and doses recommended were as follows:

- pdhC1INH: pdhC1INH was recommended, although there were no data on the most appropriate dose. In Europe, it was marketed under the following brands:

- Cinryze $^{\circledR}: 1000 \mathrm{U}$ up to 24 hours before, though there is not enough evidence that confirms that administering the drug more than 6 hours before the procedure is safe

- Berinert ${ }^{\circledR}: 1000$ U up to 6 hours before 
- $\quad$ AAs from 5 days before to 2-3 days after the procedure (STP could be considered when the risk associated with surgery was low and there was no immediate availability of the specific treatments for acute attacks)

- Danazol: 2.5-10 mg/kg/day, up to a maximum dose of $600 \mathrm{mg} /$ day

- Antifibrinolytics

- Tranexamic acid: $25 \mathrm{mg} / \mathrm{kg} /$ day (up to a maximum dose of 3000-6000 mg/day) divided into $2-3$ doses from 5 days before to $2-5$ days after the surgery or when a trigger was anticipated. Its effectiveness in preventing attacks was unknown, so it should only be used if other drugs were not available

\subsection{The 2013 Spanish algorithm for short-term prophylaxis}

A group of allergists along with clinical pharmacologists from different hospitals in Spain developed algorithms for the diagnosis, prophylaxis and treatment of C1-INH-HAE [48].

STP was not indicated in minor procedures with the availability of specific treatment for acute AE attacks. STP was indicated in all the procedures that involved trauma in the cervicofacial region because of the risk of developing $\mathrm{AE}$ in the upper airway and in any diagnostic or therapeutic procedure in order to avoid local edema in the working area so that the procedure result was not altered.

pdhC1INH was the election treatment for STP. Both Cinryze ${ }^{\circledR} 1000$ U (1-24 horas preprocedure) and Berinert ${ }^{\circledR} 10-20 \mathrm{U} / \mathrm{kg}$ (1-6 hours of pre-procedure) were available for their 20 use in adults.

In case pdhC1INH was not available, attenuated androgens (danazol, estanozolol) and antifibrinolytics (tranexamic acid, epsilon aminocaproic acid) were alternatives in programmed procedures and SD-FFP in case of emergency procedures.

- Danazol: 400-600 mg/day (divided into 2-3 doses/day-from 5 to 7 days pre-procedure to 2-3 days post-procedure)

- Stanozolol: 4-6 mg/day (divided into 2-3 doses/day - from 5 to 7 days pre-procedure to 3 days post-procedure)

- Tranexamic acid: 1,000 mg/6 hours (from 5 days pre-procedure to 2-3 days post-procedure (consider thrombotic risk)

It was advised that any patient receiving STP should be observed and the specific treatment for acute attacks should be available for 48 hours after the procedure, as the risk for AE is not totally cancelled with STP.

These authors specified STP for children. The election treatment was also intravenouspdhC1INH (Berinert ${ }^{\circledR}:$ 10-20 U/kg, 1-6 hours pre-procedure or Cinryze ${ }^{\circledR} 1000 \mathrm{U}$ ).

In case pdhC1INH was not available, they advised to use attenuated androgens or tranexamic acid: 
- Danazol: $10 \mathrm{mg} / \mathrm{kg} /$ day (divided into 2-3 doses/day-from 5 to 7 days pre-procedure to 2-3 days post-procedure)

- Tranexamic acid: $500 \mathrm{mg} / 6$ hours (from 5 days pre-procedure to $2-3$ days post-procedure)

\subsection{International consensus for the management of children with C1-INH-HAE}

According to the international consensus for the management of children [49] (Figure 4), indications for STP in paediatrics (as in adults) include patient-specific triggers, medical and dental procedures. For most "minor interventions", the recommendation is to choose an ondemand treatment if a swelling event is precipitated rather than prophylaxis, provided that a licensed on-demand medication is immediately available in the case of emergency (level III evidence).

\subsection{US consensus for the management of children with C1-INH-HAE}

Only Berinert ${ }^{\circledR}$ is approved for the treatment of children $<12$ y.o. [50]. Berinert ${ }^{\circledR}$, at $20 \mathrm{U} / \mathrm{kg}$, has less risk of containing an infectious agent, is approved by the Food and Drug Administration (FDA) in children and is preferable when available [51-53].

FFP given empirically at $2 \mathrm{U}$ per patient immediately before surgery has been reported to provide effective STP in adults and poses less risk [19]. It is critically important that effective on-demand treatment be available, whether the patient is given STP prophylaxis or not. Therapeutic approaches for C1-INH-HAE have been studied carefully in adults, but not all have not been investigated with the same level of care in children (Table 3).

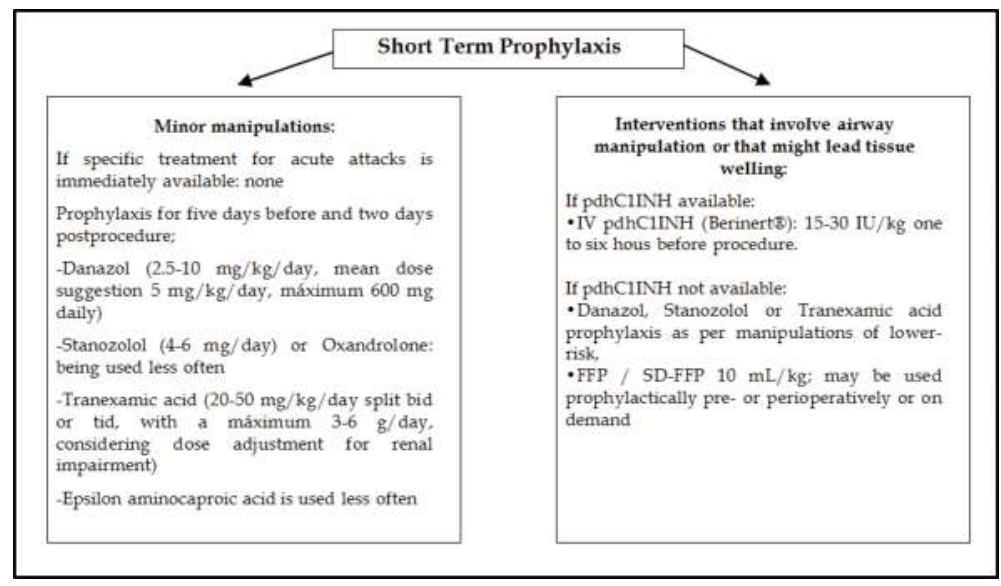

Figure 4. Prophylaxis algorithm in C1-inhibitor deficiency in the 2017 international consensus for the management of children [49]. 


\begin{tabular}{llll}
\hline Drugs & Type of evidence & Dosage & Use \\
\hline Berinert $^{\circledR}$ & I (adults) and II-3 (children) & $20 \mathrm{IU} / \mathrm{kg}$ intravenous & On demand \\
Cinryze $^{\circledR}$ & I (adults $>18$ y.o.) and II-3 (children) & $1000 \mathrm{IU}$ intravenous (adults) & Prophylaxis \\
Ruconest $^{\circledR}$ & I (adults $\geq 18$ y.o.) & $50 \mathrm{IU} / \mathrm{kg}$ intravenous & On demand \\
Icatibant acetate & I (adults $\geq 18$ y.o.) and II-3 (children) & $30 \mathrm{mg}$ subcutaneous & On demand \\
Ecallantide & I (adults, adolescents $\geq 12$ y.o.) and II-3 (children) & $30 \mathrm{mg}$ subcutaneous & On demand \\
Danazol & I (adults) and II-3 (children, not recommended) & $<200 \mathrm{mg}$ oral & Prophylaxis \\
Tranexamic acid & II-3 (adults and children) & $20-40 \mathrm{mg} / \mathrm{kg}$ up to 3 g/day oral & Prophylaxis \\
Fresh frozen plasma & II-3 (adults) & $1-2$ Units intravenous & On demand
\end{tabular}

Type of evidence I = randomized controlled trial and II-3 = dramatic results in uncontrolled trial.

Table 3. Drugs for prophylaxis and for the acute treatment of hereditary angioedema (modified Frank et al.) [50].

\subsection{Available treatments for STP in C1-INH-HAE}

\subsubsection{Plasma-derived C1 esterase inhibitor concentrate (pdhC1INH)}

pdhC1INH consists of a replacement therapy for the lacking C1-INH. There are currently several pdhC1INH pharmaceutical presentations: Berinert ${ }^{\circledR}$ (CSL-Behring GmbH, Marburg, Germany), Cebitor ${ }^{\circledR}$ (Sanquin, Amsterdam, The Netherlands) and Cinryze ${ }^{\circledR}$ (Shire HGT, Zug, Switzerland) (see Table 4 for a comparison of the available drugs for short-term prophylaxis in C1-INH-HAE).

For nearly 25 years, Berinert-P (CSL-Behring $\mathrm{GmbH}$ ) was available in Spain through the Foreign Medications office [8]. Afterwards, it was finally marketed in Spain as Berinert ${ }^{\circledR}$ in August 2009 [8]. Berinert ${ }^{\circledR}$ is a purified, pasteurized, nanofiltred pdhC1INH. It is presented in $500 \mathrm{U}$ vials of a lyophilized product for intravenous administration, which has to be stored at $2-25^{\circ} \mathrm{C}$ [8], and when reconstituted, a $50 \mathrm{IU} / \mathrm{mL}$ solution is formed. It has an excellent safety post-launch record after more than 35 years of its availability [54-56].

Berinert ${ }^{\circledR}$ is currently approved by the FDA for the treatment of AE attacks in adults and adolescents, 12 years and older, with C1-INH-HAE, and by the European Medical Agencies (EMA) for the treatment of AE attacks and short-term prophylaxis in adults and children with C1-INH-HAE [56].

Cebitor $^{\circledR}$ is only available in a few European countries.

Cinryze $^{\circledR}$ comes in a package with two lyophilized 500 U C1 inhibitor (human) vials. After reconstitution, each vial contains a $100 \mathrm{U} / \mathrm{ml}$ solution. It has to be stored from 2 to $25^{\circ} \mathrm{C}$.

The FDA approved Cinryze in October 2008 for long-term prophylaxis in adults ( $>18$ years) [8]. In 2010, the European Medicines Agency (EMA) approved the marketing of Cinryze ${ }^{\circledR}$ for long-term prophylaxis, short-term-prophylaxis and the treatment of acute attacks in adolescents and adults [57]. 


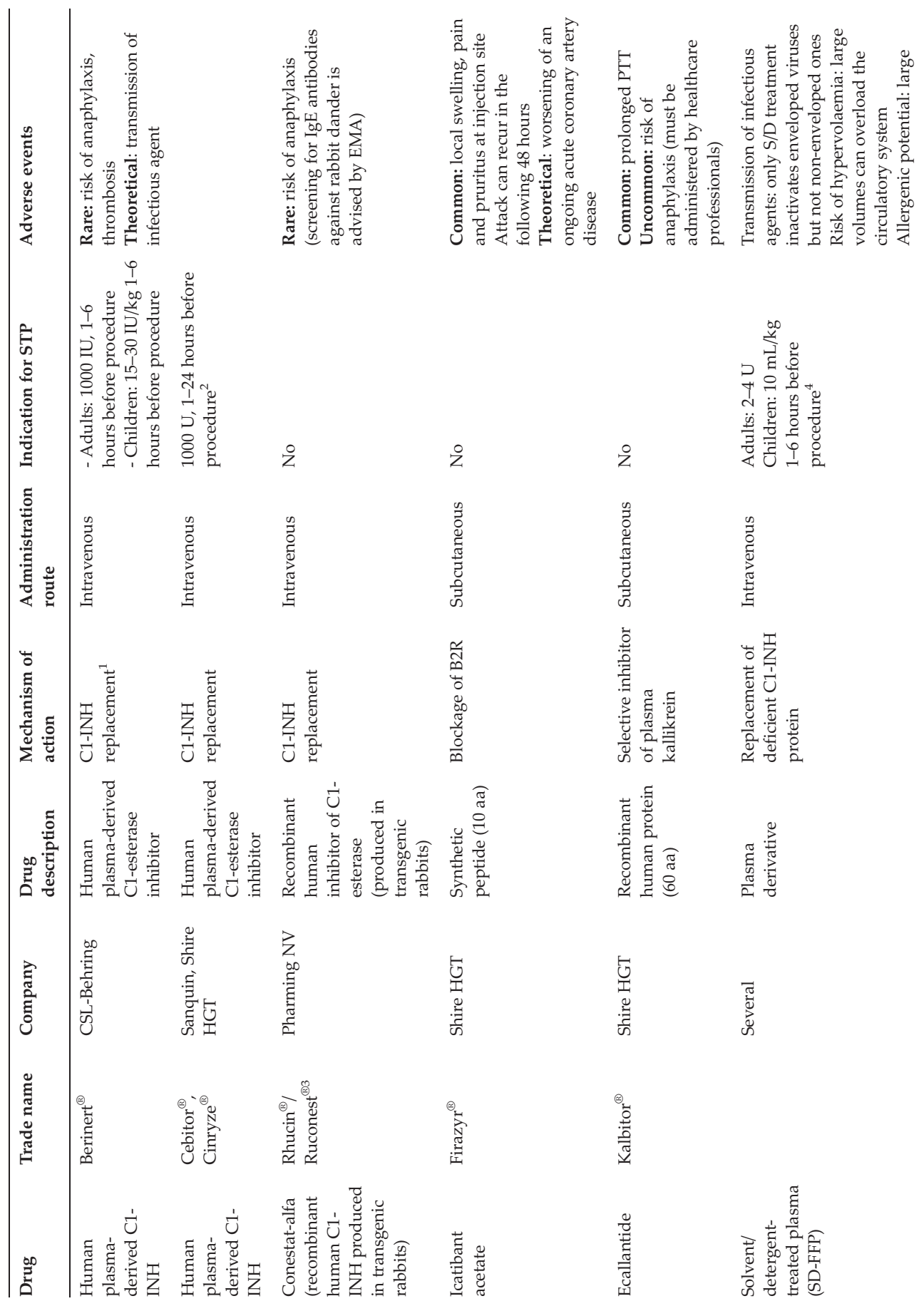




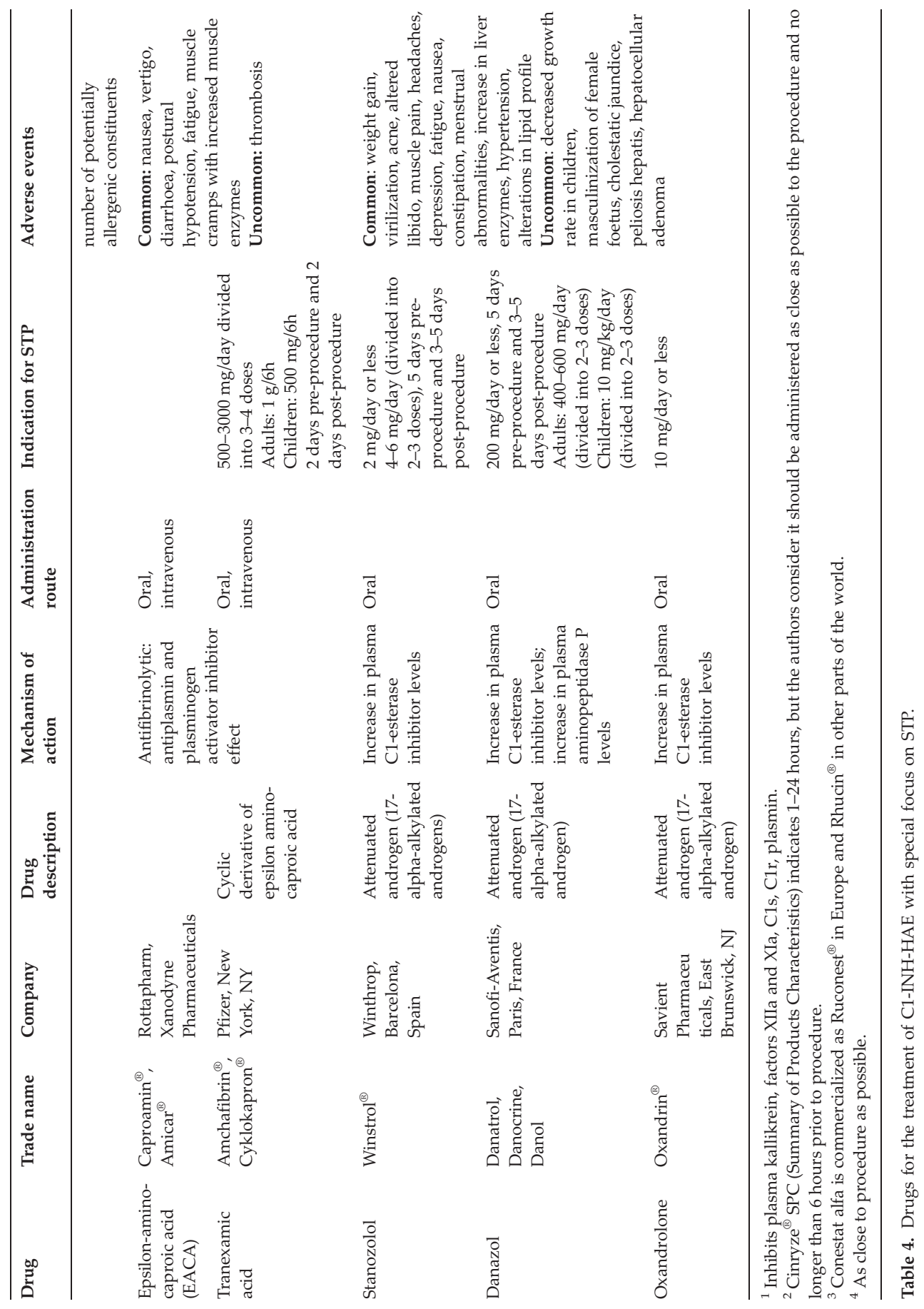


Both Berinert $^{\circledR}$ and Cinryze ${ }^{\circledR}$ are currently authorized for intravenous self-administration by trained patients or their relatives.

The recommended doses for STP are $1000 \mathrm{U}$ for adults both for Berinert ${ }^{\circledR}$ and Cinryze ${ }^{\circledR}$ and 15-30 IU/kg for children for Berinert ${ }^{\circledR}, 1-6$ hours before procedure. Although the Cinryze ${ }^{\circledR}$ Summary of Products Characteristics (SPC) indicates 1-24 hours, most authors consider that it should be administered as close as possible to the procedure and no longer than 6 hours prior to procedure [58]. For long, complex surgeries and in the case of infection or other trigger factors, the pdhC1INH dose may have to be repeated.

At least one dose of a specific drug for the treatment of acute AE attacks (C1-INH concentrate, rhC1INH, ecallantide or icatibant) should be available for on-demand treatment in case it is needed.

\subsubsection{Fresh frozen plasma}

In countries where pdhC1INH is not available, fresh frozen plasma (FFP) is an alternative. FFP should be virally inactivated with solvents and detergents (SD-FFP) to be safer. FFP acts by supplying lacking C1-INH [8]. SD-FFP dosage for C1-INH-HAE has not been studied, and the generally used dose is the same than in coagulation disorders: 2 units of $200 \mathrm{~mL}$ each [8].

Among the possible FFP side effects are alloimmunization, anaphylactic or allergic reactions, transmission of infectious diseases (viruses, Creutzfeldt-Jakob disease) and excessive intravascular volume with the risk of hypervolemia and heart failure [8].

\subsubsection{Attenuated androgens}

Danazol and stanozolol are 17- $\alpha$-alkylated synthetic derivatives, which are very effective and have fewer side effects than other androgens. Their mechanism of action in C1-INH-HAE is not well known. Several actions may contribute to their effectiveness. First, a significant increase in C1-INH plasma levels was reported with high AA doses. Second, an increase in the expression of C1-INH mRNA in mononuclear cells with the minimum effective dose was shown. Finally, an increase in the plasma levels of aminopeptidase P, one of the BK catabolizing enzymes, was published [8].

Danazol is a potent gonadotropic inhibitor with partial antigestagenic, anabolic and androgenic activity, whereas stanozolol is an anabolic steroid with certain anticoagulant properties [8].

Oxandrolone is another AA, which has been used in C1-INH-HAE to a lesser extent [8].

AAs have considerable side effects when used as long-term prophylaxis for long periods of time or at high doses [8]. The main secondary effects are disorders of libido, impotence, weight gain, menstrual irregularities, breast atrophy/hypotrophy, acne, voice changes, increased atherogenic index, polycythemia, hypertension, haematuria, transient increases in transaminases, hepatic necrosis, cholestatic hepatitis, hepatosplenic peliosis, transient increases in muscle enzymes (creatine phosphokinase and aldolase) and rhabdomyolysis. There have also been some cases of hepatic adenoma and adenocarcinoma. However, the data on increased risk of atherosclerosis are controversial. AAs used for short periods of time as STP are much better tolerated, and thus, they were advised as STP for children and pregnant women in the first consensus documents on C1-INH-HAE. 
The effect of AAs takes approximately 5 days, and thus, AAs cannot be used in emergency situations that require STP. AA doses for STP can be seen in Table 3.

These drugs may have to be administered for more than 5 days after the procedure in the case of postoperative complications, especially infection [8].

\subsubsection{Antifibrinolytic agents}

The mechanism of action of antifibrinolytic agents in C1-INH-HAE is unknown.

\subsubsection{1. $\varepsilon$-Aminocaproic acid}

$\varepsilon$-Aminocaproic acid (EACA) (Amycar ${ }^{\circledR}$, Rottapharm Madaus, Milan, Italy) is effective in preventing AE attacks in C1-INH-HAE if taken as long-term prophylaxis [8, 14]. There is a scarcity of data about its use as STP, although some consensus documents advise on its use [13,44].

The most frequent side effect is a transient increase in creatine phosphokinase and aldolase associated with muscle pain, weakness and fatigue. Other side effects are thrombosis and extensive muscle necrosis [8].

\subsubsection{Tranexamic acid}

Tranexamic acid (Amchafibrin ${ }^{\circledR}$, Rottapharm Madaus, Milan, Italy) is a cyclic derivative of EACA and has been proven efficacious in preventing AE attacks in patients with C1-INH-HAE $[8,14]$. Tranexamic acid competitively inhibits the activation of plasminogen, which, under normal conditions, is inhibited by $\mathrm{C} 1-\mathrm{INH}$, thus reducing the conversion of plasminogen to plasmin (fibrinolysis) [8].

Muscle cramps, nausea, diarrhoea, hypotension, dizziness and fatigue are among its described side effects.

The dose for STP is $1 \mathrm{~g} 4$ times a day or $75 \mathrm{mg} / \mathrm{kg} /$ day divided into $2-3$ doses from 5 days before to 2 days after the surgery or medical procedure.

Antifibrinolytics are seldom used in countries where other treatments are available. Antifibrinolytics should be discontinued before the surgery, as they may theoretically promote thromboembolic events [8].

\subsubsection{Icatibant acetate}

Icatibant acetate (Firazyr ${ }^{\circledR}$, Shire HGT, Zug, Switzerland) is a synthetic decapeptide similar to BK and a highly specific, potent and competitive antagonist of the BK B2 receptor (B2R), inhibiting the vasodilation produced by BK [8]. Its effectiveness as the treatment for AE acute attacks in C1-INH-HAE has been shown in clinical trials and patient series [8] and in patient registries [59-61]. No serious adverse reactions have been reported, the only significant side effect being injection site reactions (in more than 95\% of cases), consisting of self-limiting erythema, oedema, pruritus and pain [8]. The European Medicines Agency (EMA) approved icatibant acetate for the treatment of acute AE attacks in adult patients ( $\geq 18$ y.o.) with C1-INHHAE in July 2008, and it has been available in Spain since March 2009. It was approved by the 
FDA in 2011. Icatibant acetate's self-administration was authorized by EMA in 2011. A registry on the use of icatibant acetate in real life has confirmed its safety [61].

Icatibant acetate is only approved for adults. A study on its safety and efficacy in children is currently going on. There is no information about its safety profile in women who are pregnant. Regarding breastfeeding, lactation should be avoided 12 hours after icatibant acetate's administration. According to prescribing information, icatibant acetate should not be used in patients with active ischemic heart disease or those who have had an ischemic stroke in the preceding 2 weeks [8].

Isolated cases of STP with off-label icatibant acetate prior to some medical, dental or surgical procedures in patients with C1-INH-HAE have been published [38, 62, 63]. First, a thyroid biopsy without later local oedema was published [62].

However, controlled studies are necessary. The short half-life (1-2 hours) of this agent and the fact that it blocks B2R but does not diminish the BK production may restrict its use in shortterm prophylaxis, as there is a theoretical risk of late local oedema. The trauma may result in an increase in local BK through FXII activation. While B2R blockage continues, no oedema is produced, but when B2Rs are released (after icatibant is eliminated from the body), an oedema episode could develop 6-8 hours after the surgery if BK remains high [8]. Other authors do not support its use as short-term prophylaxis due to its short half-life [64].

\subsubsection{Ecallantide (Kalbitor ${ }^{\circledR}$, Shire HGT, Zug, Switzerland)}

Ecallantide is a very potent, reversible and highly specific human plasma kallikrein inhibitor, whose half-life is $2.0 \pm 0.5$ hours [8]. Its effectiveness has been demonstrated in different clinical trials $[8,14,58,65]$.

The United States Food and Drug Administration approved its use in December 2009 for the treatment of acute AE episodes in patients aged 16 years and older with C1-INH-HAE. Later, its use was extended to adolescents.

Acute allergic reactions, as well as anaphylaxis, have been reported [8].

It is administered subcutaneously at $30 \mathrm{mg}$ (divided into 3 doses) and should be stored refrigerated [8]. One isolated case of STP with a low dose of ecallantide $(10 \mathrm{mg})$ plus FFP, which did not result in AE, was reported [66].

However, the short half-life of ecallantide $(2.0 \pm 0.5$ hours $)$ could restrict its use as short-term prophylaxis $[8,64]$. It is necessary to carry out controlled studies or gain more experience in order to recommend its use in this indication.

\subsubsection{Recombinant human C1 inhibitor}

Recombinant human C1-INH (rhC1INH) (Ruconest ${ }^{\circledR} /$ Rhucin $^{\circledR}$, Pharming Group NV, Leiden, The Netherlands) is produced in transgenic female rabbits in which the human $\mathrm{C} 1 \mathrm{NH}$ gene has been inserted. The resulting rhC1INH is excreted in the rabbit milk, from which it is obtained by purification. The active substance is also termed conestat alfa. rhC1INH is effective in the treatment of acute AE attacks. rhC1INH is a C1-INH replacement therapy but with 
the advantages of the absence of the potential risk of transmitting blood-borne human infections and its suitability for large-scale production. It has a similar inhibitory potency and high structural analogy with phC1INH, although with a lower half-life (3 hours), due to differences in glycosylation. rhC1INH can be kept at room temperature $\left(2-25^{\circ} \mathrm{C}\right)$. A $50 \mathrm{U} / \mathrm{kg}$ dose (maximum $4200 \mathrm{U}$ ) was approved by the EMA in October 2010 for the treatment of acute AE attacks in > 18 years with C1-INH-HAE, although it has not yet been marketed in Spain. In 2016, its approval was extended to adolescents.

FDA approved rhC1INH in 2014 for the treatment of acute AE attacks in adolescents and adult patients with C1-INH-HAE. The approved dose is $50 \mathrm{U} / \mathrm{kg}$ with a maximum dose of $4200 \mathrm{U}$ administered intravenously.

A possible disadvantage of recombinant products is being potentially immunogenic and having the risk of producing neutralizing antibodies and/or allergic reactions. However, data on immunological safety are good, with no antibody production and no adverse immunological effects observed, except for an anaphylactic reaction in one patient with undisclosed rabbit allergy in a phase I clinical trial [8,57].

rhC1INH is not recommended for short-term prophylactic management of C1-INH-HAE due to its short half-life [64].

Two consensus for the management of C1-INH-HAE in children have been published in 22 $2016[50,65,66]$.

Caballero et al. published a consensus document in which the management of STP in female patients was reviewed [67]. This information was updated later for HAE with and without C1-inhibitor deficiency [68].

The unavailability of STP should not delay an urgent procedure [69]. C1-INH-HAE should not be an obstacle for routine procedures [69].

In DOMFOP, it is advisable, provided that it is possible, to use regional anaesthesia to avoid the trauma that supposes oropharyngeal intubation $[8,13,70]$.

It is impossible to predict which patients will develop angioedema after a determined medical/ surgical procedure. Moreover, a single patient could present or not present AE after the same procedure [70-72]. There are no controlled studies that assess STP efficacy; current available data come from observational studies: The risk of perioperative AE without STP (not taking into account dental procedures) is $6-31 \%$ [73]. There is no increased risk related to the procedure location or surgical area size [73]. The prevalence of AE attacks after dental procedures performed without STP varies from 5 to $37 \%$ of patients [71-73]. Farkas et al. observed that $40 \%$ of the patients who had not performed STP developed AE post-procedures, when assessing all the interventions as a whole [74]. Most times, $\mathrm{AE}$ is local, but distant $\mathrm{AE}$ has also been described $[72,73]$. AE can be triggered by minor procedures, such as local injection of a local anesthetic [43], suture of a hand cut or an aesthetic injection of hyaluronic acid in the lips [72]. In some patients, perioperative angioedema was the first manifestation of C1-INH-HAE [72].

The study of STP use in large patients' series has shown that STP with pdhC1INH or AAs reduced the number of patients who present $\mathrm{AE}$ attacks after medical/surgical procedures [15, 71, 73]. 
pdhC1INH reduced the AE risk more after invasive procedures than AAs and AAs more than tranexamic acid [73]. It is important to emphasize that the AE risk after surgical/medical procedures is not completely avoided with STP [71, 73] and is independent of C1-INH-HAE severity [15] and thus, at least one therapeutic dose of a specific treatment for acute AE attacks should be available during and after the procedure [8,74]. If the procedure involves the ENT area, the patient should be informed about the possibility to develop a laryngeal oedema, not only in the 12 hours following the procedure but also later [72], and one should establish an action plan for the patient.

\section{Conclusion: a proposal for STP algorithm}

Based on the clinical experience of the Department of Allergology of the University Hospital La Paz (Madrid) and the University General Hospital Nuestra Señora del Prado (Talavera de la Reina), these algorithms have been updated and modified.

Most studies do not take into account the disease severity in order to plan STP and to study the STP efficacy.

Jurado-Palomo et al. [15] calculated retrospectively the C1-INH-HAE severity by using the Diagnostic, Therapeutic, and Management Algorithm for Hereditary Angioedema, from Agostoni et al. [70] (Table 5). They studied the efficacy of STP with AAs and/or pdhC1INH in patients with C1-INH-HAE and found that all the patients who suffered mild pharynx laryngeal AE curiously occurred in the group of patients with milder stages of C1-INH-HAE. Curiously, these patients had not received long- or short-term AA prophylaxis nor pre-procedural pdhC1INH [15].

\begin{tabular}{|c|c|c|}
\hline \multicolumn{2}{|c|}{ Attack severity } & Score \\
\hline \multicolumn{2}{|c|}{ Mild attacks (discomfort noticed, but no disruption of normal daily activities) } & 0.5 for each 24 hours \\
\hline \multicolumn{2}{|c|}{ Moderate attacks (discomfort sufficient to reduce or affect normal daily activities) } & 1 for each 24 hours \\
\hline \multicolumn{2}{|c|}{ Severe attacks (inability to work or perform daily activity) } & 2 for each 24 hours \\
\hline \multicolumn{3}{|c|}{ Need for treatment: } \\
\hline \multicolumn{2}{|c|}{ - Emergency treatment: conservative, substitutive (C1-INH, FFP). } & 5 each \\
\hline \multicolumn{2}{|c|}{ - Emergency treatment: invasive (intubation, tracheotomy). } & 25 each \\
\hline \multicolumn{2}{|c|}{ - Long-term prophylaxis for more than 6 months. } & 25 \\
\hline \multicolumn{2}{|c|}{ - Long-term prophylaxis for 3-6 months. } & 12.5 \\
\hline Score & Class & Degree \\
\hline$>30$ & 1 & Severe \\
\hline $21-30$ & 2 & Moderate \\
\hline $11-20$ & 3 & Mild \\
\hline $1-10$ & 4 & Minimal \\
\hline 0 & 5 & Asymptomatic \\
\hline
\end{tabular}

Table 5. Criteria for the evaluation of disease severity [70] (these parameters are determined over the period of 1 year. The sum of the scores defines the severity of the disease for that year). 
We advise to classify procedures according to the risk of producing AE as minor, intermediate and major risks.

If we classified dental procedures according to the surgical risk, the injection of local anaesthetic would be of minor AE risk, but it has been identified to be able to precipitate an attack of AE [43]. In our series, even the placement of orthodontic appliances (lower risk according to our classification) showed triggering of mild palate oedema in the months after the placement [15]. Thus, it is important that patients have specific drugs, for the treatment of acute attacks, available.

We would recommend using danazol, stanozolol and tranexamic acid in minor risk manipulations and not using tranexamic acid for those procedures of intermediate or major AE risk and attenuated androgens if pdhC1INH is available.

Given this and in our experience, we would propose the following algorithms for the prophylaxis of DOMFOPs (Figure 5). To elaborate on this algorithm, three special mentions can be done:

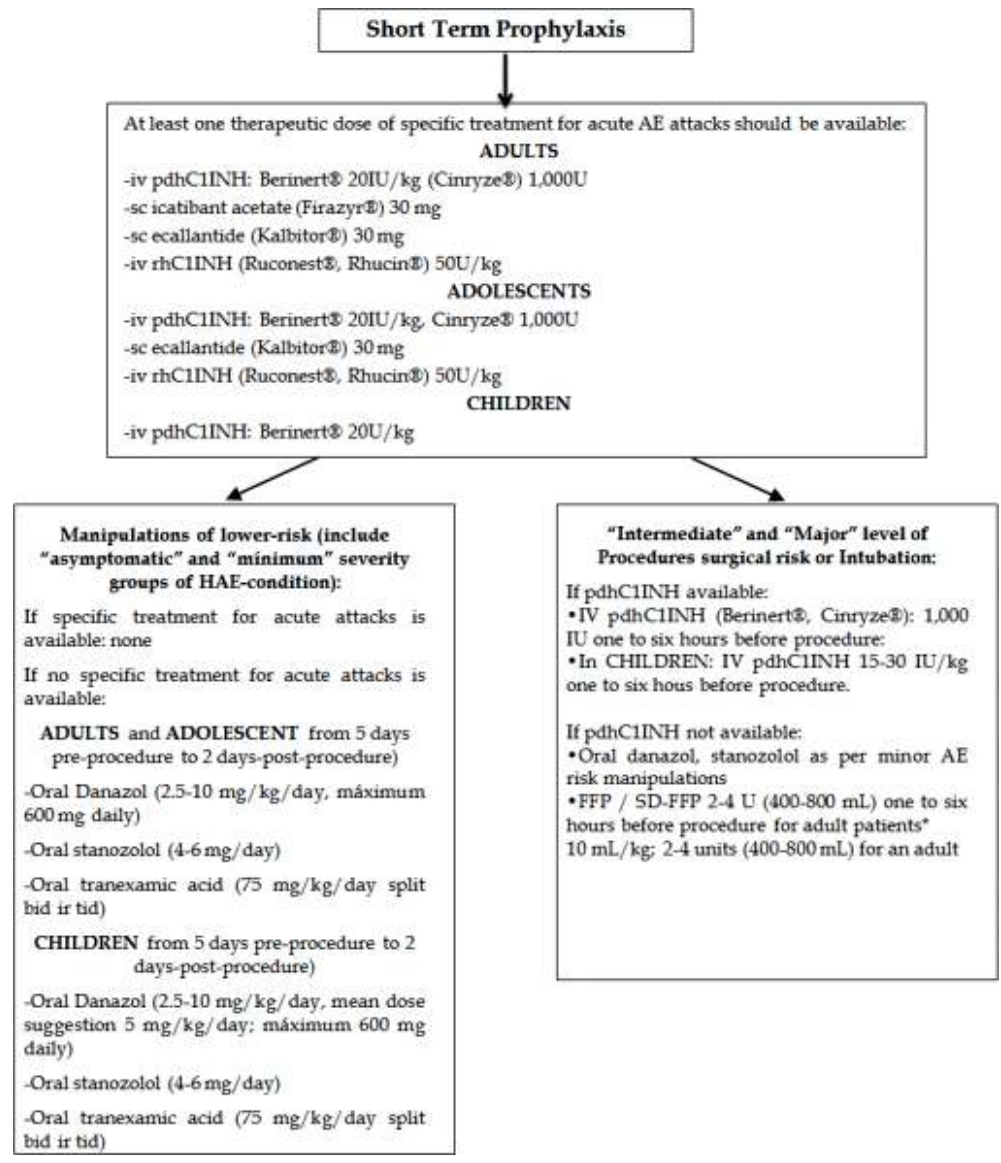

Figure 5. Proposed algorithm for short-term prophylaxis in C1-INH-HAE according to the authors' experience at University Hospital La Paz in Madrid and at University General Hospital Nuestra Señora del Prado in Talavera de la Reina. 
1. In an "intermediate" level of procedures, surgical risk is included, although it includes the same prophylactic approach as greater surgical risk.

2. It is clearly specified that short-term prophylaxis to reduce AE risk after dental manipulations should be performed even in patients with asymptomatic activity or minimal disease.

3. Stanozolol is included as a recommendation in lower risk manipulations, at the same level as danazol or tranexamic acid.

Close coordination between different specialists is advisable to decide the attitude to follow pre-procedurally. Treatment for acute attacks should be available in the operating room, in the allergology department and even at patient's home.

\section{Author details}

Jesús Jurado-Palomo ${ }^{1,2 *}$ and Teresa Caballero ${ }^{2,3,4}$

*Address all correspondence to: h72jupaj@yahoo.es

1 Department of Allergology, Nuestra Señora del Prado University General Hospital, Talavera de la Reina, Spain

2 Spanish Study Group on Bradykinin-Induced Angioedema (SGBA), Spanish Society of Allergology and Clinical Immunology (SEAIC), Spain

3 Department of Allergology, Hospital La Paz Health Research Institute (IdiPAZ), Madrid, Spain

4 Biomedical Research Network on Rare Diseases, CIBERER (U754), Madrid, Spain

\section{References}

[1] Caballero T, Baeza ML, Cabañas R, Campos A, Cimbollek S, Gómez-Traseira C, et al. Consensus statement on the diagnosis, management, and treatment of angioedema mediated by bradykinin. Part I. Classification, epidemiology, pathophysiology, genetics, clinical symptoms, and diagnosis. J Investig Allergol Clin Immunol. 2011;21:333-47; quiz follow 347. Review. Erratum in: J Investig Allergol Clin Immunol. 2012;22:3 p following 153.

[2] Roche O, Blanch A, Caballero T, Sastre N, Callejo D, López-Trascasa M. Hereditary angioedema due to $\mathrm{C} 1$ inhibitor deficiency: patient registry and approach to the prevalence in Spain. Ann Allergy Asthma Immunol. 2005;94:498-503.

[3] Bygum A. Hereditary angio-oedema in Denmark. A nationwide survey. Br J Dermatol 2009;161:1153-8. 
[4] Zanichelli A, Arcoleo F, Barca MP, Borrelli P, Bova M, Cancian M, et al. A nationwide survey of hereditary angioedema due to $\mathrm{C} 1$ inhibitor deficiency in Italy. Orphanet J Rare Dis. 2015;10:11.

[5] Stray-Pedersen A, Abrahamsen TG, Frøland SS. Primary immunodeficiency diseases in Norway. J Clin Immunol. 2000;20:477-85.

[6] Fay A, Abinun M. Current management of hereditary angioedema (C1 esterase inhibitor deficiency). J Clin Pathol 2002;55:266-70.

[7] Atkinson JC, Frank MM. Oral manifestations and dental management of patients with hereditary angioedema. J Oral Pathol Med. 1991;20:139-42.

[8] Caballero T, Baeza ML, Cabañas R, Campos A, Cimbollek S, Gómez-Traseira C, et al. Consensus statement on the diagnosis, management, and treatment of angioedema mediated by bradykinin. Part II. Treatment, follow-up, and special situations. J Investig Allergol Clin Immunol. 2011;21:422-41; quiz 442-3. Review. Erratum in: J Investig Allergol Clin Immunol. 2012;22:3 p following 153.

[9] Bork K, Barnstedt SE. Laryngeal edema and death from asphyxiation after tooth extraction in four patients with hereditary angioedema. J Am Dent Assoc. 2003;134:1088-94.

[10] Landerman NS. Hereditary angioneurotic edema. J Allergy Clin Immunol. 1962;33:316-29.

[11] Cicardi M, Bergamaschini L, Marasini B, Boccassini G, Tucci A, Agostoni A. Hereditary angioedema: an appraisal of 104 cases. Am J Med Sci. 1982;284:2-9.

[12] Bork K, Siedlecki K, Bosch S, Schopf RE, Kreuz W. Asphyxiation by laryngeal edema in patients with hereditary angioedema. Mayo Clin Proc. 2000;75:349-54.

[13] Bowen T, Cicardi M, Farkas H, Bork K, Longhurst HJ, Zuraw B, et al. International consensus algorithm for the diagnosis, therapy and management of hereditary angioedema. Allergy Asthma Clin Immunol. 2010;6:24-36.

[14] Cicardi M, Bork K, Caballero T, Craig T, Li HH, Longhurst H, et al. Evidence-based recommendations for the therapeutic management of angioedema owing to hereditary C1 inhibitor deficiency: consensus report of an International Working Group. Allergy. 2012;67:147-57.

[15] Jurado-Palomo J, Muñoz-Caro JM, López-Serrano MC, Prior N, Cabañas R, Pedrosa M et al. Management of dental-oral procedures in patients with hereditary angioedema due to C1 inhibitor deficiency. J Investig Allergol Clin Immunol. 2013;23:1-6.

[16] Gompels MM, Lock RJ, Abinun M, Bethune CA, Davies G, Grattan C, et al. C1 inhibitor deficiency: consensus document. Clin Exp Immunol. 2005;139:379-94.

[17] Wall RT, Frank M, Hahn M. A review of 25 patients with hereditary angioedema requiring surgery. Anesthesiology. 1989;71:309-11.

[18] Bork K, Barnstedt SE. Laryngeal edema and death from asphyxiation after tooth extraction in four patients with hereditary angioedema. J Am Dent Assoc. 2003;134:1088-94. 
[19] Jaffe CJ, Atkinson JP, Gelfand JA, Frank MM. Hereditary angioedema: the use of fresh frozen plasma for prophylaxis in patients undergoing oral surgery. J Allergy Clin Immunol. 1975;55:386-93.

[20] Heft MW, Flynn PM. Hereditary angioedema: review of literature and dental treatment. J Am Dent Assoc. 1977;95:986-90.

[21] Delfino JJ, Sclaroff A, Giglio JA, Travis M. Management of a patient with hereditary angioneurotic edema. J Oral Surg. 1978;36:890-2.

[22] Albright BW, Taylor CG. Hereditary angioneurotic edema: report of case. J Oral Surg. 1979;37:888-90.

[23] Sturdy KA, Beastall RH, Grisius RJ, Oatis GW Jr. Hereditary angioedema controlled with danazol. Report of a case. Oral Surg Oral Med Oral Pathol. 1979;48:418-20.

[24] Mauro JV, Meyrowitz MR, Licari G, Jankowski R. Hereditary angioneurotic edema: clinical management and case report. J Am Dent Assoc. 1982;104:641-3.

[25] Malmstrom HS, Hock JM, Sandforf C. Dental management of patients with hereditary angioedema: report a case. J Am Dent Assoc. 1985;111:957-8.

[26] Degroote DF, Smith GL, Huttula GS. Acute airway obstruction following tooth extraction in hereditary angioedema. J Oral Maxillofac Surg. 1985;43:52-4.

[27] Phillips KM, Glock M, Cohen SG. Hereditary angioedema: report of case. Spec Care Dentist. 1989;9:23-6.

[28] Leimgruber A, Jacques WA, Spaeth PJ. Hereditary angioedema: uncomplicated maxillofacial surgery using short-term C1 inhibitor replacement therapy. Inn Arch Allergy Immunol. 1993;101:107-12.

[29] Peled M, Ardekian L, Schnarch A, Laufer D. Preoperative prophylaxis for C1 esteraseinhibitor deficiency in patients undergoing oral surgery: a report of three cases. Quintessence Int. 1977;28:169-71.

[30] Karlis V, Glickman RS, Stern R, Kinney L. Hereditary angioedema: case report and review of management. Oral Surg Oral Med Oral Pathol Oral Radiol Endod. 1997;83:462-4.

[31] Farkas H, Gyeney L, Gidofalvy E, Fust G, Varga L. The efficacy of short-term danazol prophylaxis in hereditary angioedema patients undergoing maxillofacial and dental procedures. J Oral Maxillofac Surg. 1999;57:404-8.

[32] Webb MD, Hakimeh S, Holly LK. Management of children with hereditary angioedema: a report of two cases. Pediatr Dent. 2000;22:141-3.

[33] Maeda S, Miyawaki T, Nombra S, Yagi T, Shimada M. Management of oral surgery in patients with hereditary or acquired angioedemas: review and case report. Oral Surg Oral Med Oral Pathol Oral Radiol Endod. 2003;96:540-3. 
[34] Rice S, Cochrane TJ, Millwaters M, Ali NT. Emergency management of upper airway angio-oedema after routine dental extraction in a patient with $\mathrm{C} 1$ esterase deficiency. $\mathrm{Br} \mathrm{J}$ Oral Maxillofac Surg. 2008;46:394-6.

[35] Van Sickels NJ, Hunsaker RB, Van Sickels JE. Hereditary angioedema: treatment, management, and precautions in patients presenting for dental care. Oral Surg Oral Med Oral Pathol Oral Radiol Endod. 2010;109:168-72.

[36] Moraes RS, Vieira AS, Primo LG. Management of a dentigerous cyst in a child with hereditary angioedema. J Dent Child (Chic). 2010;77:59-63.

[37] Baccioglu Kavut A. A case of hereditary angioedema type II diagnosed in adult age by his first and life-threatening attack. Allergy 2011;66(Suppl. 94):320-481 (p. 431).

[38] Senaratne KT, Cottrell AM, Prentice RI. Successful perioperative management of a patient with $\mathrm{C} 1$ esterase inhibitor deficiency with a novel bradykinin receptor B2 antagonist. Anaesth Intens Care. 2012;40:523-6.

[39] Angeletti C, Angeletti PM, Mastrobuono F, Pilotti L, Ciccozzi A, Guetti C. BradykininB2 receptor antagonist off label use in short-term prophylaxis in hereditary angioedema. Int J Immunopathol Pharmacol. 2014;27:653-9.

[40] Narayanan A, Date RR, Birur S, Bhakta P, Srinivasan S. Anaesthesia management of a patient with hereditary angioedema with prophylactic administration of C1 esterase inhibitor: case report and literature review. Sultan Qaboos Univ Med J. 2013;13:E467-71.

[41] Sanuki T Watanabe T, Kurata S, Ayuse T. Perioperative management of tooth extractions for a patient with hereditary angioedema. J Oral Maxillofac Surg. 2014;72:2421.e1-3.

[42] Forrest A, Milne N, Soon A. Hereditary angioedema: death after a dental extraction. Aust Dent J. 2016. doi:10.1111/adj.12447.

[43] Bowen T, Cicardi M, Farkas H, Bork K, Kreuz W, Zingale L, et al. Canadian 2003 international consensus algorithm for the diagnosis, therapy, and management of hereditary angioedema. J Allergy Clin Immunol. 2004;114:629-37.

[44] Bowen T, Cicardi M, Bork K, Zuraw B, Frank M, Ritchie B, et al. Hereditary angiodema: a current state-of-the-art review, VII: Canadian Hungarian 2007 international consensus algorithm for the diagnosis, therapy, and management of hereditary angioedema. Ann Allergy Asthma Immunol. 2008;100(1 Suppl 2):S30-40.

[45] Craig T, Aygören-Pürsün E, Bork K, Bowen T, Boysen H, Farkas H, et al. WAO guideline for the management of hereditary angioedema. World Allergy Organ J. 2012;5:182-99.

[46] Zuraw BL, Bernstein JA, Lang DM, Craig T, Dreyfus D, Hsieh F, et al. A focused parameter update: hereditary angioedema, acquired $\mathrm{C} 1$ inhibitor deficiency, and angiotensin-converting enzyme inhibitor-associated angioedema. J Allergy Clin Immunol. 2013;131:1491-3. 
[47] Betschel S, Badiou J, Binkley K, Hébert J, Kanani A, Keith P, et al. Canadian hereditary angioedema guideline. Allergy Asthma Clin Immunol. 2014;10:50.

[48] Baeza ML, Caballero Molina T, Crespo Diz C, González-Quevedo, Guilarte Clavero M, Hernández Fernández de Rojas D, et al. Algorithm for diagnosis and treatment of hereditary angioedema as a tool for management. Farm Hosp. 2013;37:521-9. Erratum in: Farm Hosp. 2014;38:150.

[49] Farkas H, Martinez-Saguer I, Bork K, Bowen T, Craig T, Frank M, et al. International consensus on the diagnosis and management of pediatric patients with hereditary angioedema with C1 inhibitor deficiency. Allergy. 2017;72:300-313.

[50] Frank MM, Zuraw B, Banerji A, Bernstein JA, Craig T, Busse P, et al. Management of children with hereditary angioedema due to C1 Inhibitor deficiency. Pediatrics. 2016;138(5). pii: e20160575.

[51] Schneider L, Hurewitz D, Wasserman R, Obtulowicz K, Machnig T, Moldovan D, et al. C1-INH concentrate for treatment of acute hereditary angioedema: a pediatric cohort from the I.M.P.A.C.T. studies. Pediatr Allergy Immunol. 2013;24:54-60.

[52] Lumry W, Manning ME, Hurewitz DS, Davis-Lorton M, Fitts D, Kalfus IN, et al. Nanofiltered C1-esterase inhibitor for the acute management and prevention of hereditary angioedema attacks due to C1-inhibitor deficiency in children. J Pediatr. 2013;162:1017-22, e1-2.

[53] Frank MM. Update on preventive therapy (prophylaxis) of hereditary angioedema. Allergy Asthma Proc. 2011;32:17-21.

[54] De Serres J, Groner A, Lindner J. Safety and efficacy of pasteurized C1 inhibitor concentrate (Berinert P) in hereditary angioedema: a review. Transfus Apher Sci. 2003;29:247-54.

[55] Terpstra FG, Kleijn M, Koenderman AH, Over J, van Engelenburg FA, Schuitemaker H, van't Wout AB. Viral safety of C1-inhibitor NF. Biologicals. 2007;35:173-81.

[56] Riedl MA, Bygum A, Lumry W, Magerl M, Bernstein JA, Busse P, et al. Safety and usage of C1-inhibitor in hereditary angioedema: Berinert registry data. J Allergy Clin Immunol Pract. 2016;4:963-71.

[57] Caballero Molina T, Pedrosa Delgado M, Gómez Traseira C. Hereditary angioedema. Med Clin (Barc). 2015;145:356-65.

[58] Cicardi M, Aberer W, Banerji A, Bas M, Bernstein JA, Bork K, et al. Classification, diagnosis, and approach to treatment for angioedema: consensus report from the hereditary angioedema international working group. Allergy. 2014;69:602-16.

[59] Hernández Fernández de Rojas D, Ibañez E, Longhurst H, Maurer M, Fabien V, Aberer $\mathrm{W}$, et al. Treatment of HAE attacks in the icatibant outcome survey: an analysis of icatibant self-administration versus administration by health care professionals. Int Arch Allergy Immunol. 2015;167:21-8. 
[60] Longhurst HJ, Aberer W, Bouillet L, Caballero T, Fabien V, Zanichelli A, et al. Analysis of characteristics associated with reinjection of icatibant: results from the icatibant outcome survey. Allergy Asthma Proc. 2015;36:399-406. Erratum in: Allergy Asthma Proc. 2015;36:511.

[61] Zanichelli A, Maurer M, Aberer W, Caballero T, Longhurst H, Bouillet L, et al. Long-term safety of icatibant treatment of patients with angioedema in real-world clinical practice. Allergy. 2016. doi:10.1111/all.13103.

[62] Marqués L, Domingo D, Maravall FJ, Clotet J. Short-term prophylactic treatment of hereditary angioedema with icatibant. Allergy. 2010;65:137-8.

[63] Angeletti C, Angeletti PM, Mastrobuono F, Pilotti L, Ciccozzi A, Guetti C. Bradykinin B2 receptor antagonist off label use in short-term prophylaxis in hereditary angioedema. Int J Immunopathol Pharmacol. 2014;27:653-9.

[64] Bernstein JA. Managing hereditary angioedema patients undergoing otolaryngeal procedures. Am J Rhinol Allergy. 2013;27(6):522-7. doi:10.2500/ajra.2013.27.3964.

[65] Turner MD, Oughourli A, Heaney K, Selvaggi T. Use of recombinant plasma kallikrein inhibitor in hereditary angioedema: a case report and review of the management of the disorder. J Oral Maxillofac Surg. 2004;62:1553-6.

[66] Farkas H, Martinez-Saguer I, Bork K, Bowen T, Craig T, Frank M, et al. International consensus on the diagnosis and management of pediatric patients with hereditary angioedema with C1 inhibitor deficiency. Allergy. 2016. doi:10.1111/all.13001.

[67] Caballero T, Farkas H, Bouillet L, Bowen T, Gompel A, Fagerberg C, et al. International consensus and practical guidelines on the gynecologic and obstetric management of female patients with hereditary angioedema caused by C1 inhibitor deficiency. J Allergy Clin Immunol. 2012;129:308-20.

[68] Caballero T, Canabal J, Rivero-Paparoni D, Cabañas R. Management of hereditary angioedema in pregnant women: a review. Int J Womens Health. 2014;6:839-48.

[69] Longhurst H, Cicardi M. Hereditary angio-oedema. Lancet. 2012;379(9814):474-81.

[70] Agostoni A, Aygören-Pürsün E, Binkley KE, Blanch A, Bork K, Bouillet L, et al. Hereditary and acquired angioedema: problems and progress: proceedings of the third $\mathrm{C} 1$ esterase inhibitor deficiency workshop and beyond. J Allergy Clin Immunol. 2004;114: S51-131.

[71] Bork K, Hardt J, Staubach-Renz P, Witzke G. Risk of laryngeal edema and facial swellings after tooth extraction in patients with hereditary angioedema with and without prophylaxis with $\mathrm{C} 1$ inhibitor concentrate: a retrospective study. Oral Surg Oral Med Oral Pathol Oral Radiol Endod. 2011;112:58-64.

[72] Aygören-Pürsün E, Martinez Saguer I, Kreuz W, Klingebiel T, Schwabe D. Risk of angioedema following invasive or surgical procedures in HAE type I and II--the natural history. Allergy. 2013;68:1034-9. 
[73] Farkas H, Zotter Z, Csuka D, Szabó E, Nébenfuhrer Z, Temesszentandrási G, et al. Shortterm prophylaxis in hereditary angioedema due to deficiency of the C1-inhibitor--a longterm survey. Allergy 2012;67:1586-93.

[74] Zuraw B, Bersntein J, Lang D. A focused parameter update: hereditary angioedema, acquired $\mathrm{C} 1$ inhibitor deficiency, and angiotensin-converting enzyme inhibito-associated angioedema. J Allergy Clin Immunol. 2013;131:1491-3. 